\title{
Correction to: (New) Methods for Detection of Aspergillus fumigatus Resistance in Clinical Samples
}

\author{
Jeffrey D. Jenks ${ }^{1} \cdot$ Birgit Spiess $^{2}$ - Dieter Buchheidt ${ }^{2} \cdot$ Martin Hoenigl ${ }^{1,3}$
}

Published online: 10 July 2019

(C) Springer Science+Business Media, LLC, part of Springer Nature 2019

\section{Correction to: Curr Fungal Infect Rep (2019) https://doi.org/10.1007/s12281-019-00342-w}

Funding information was incomplete. The correct information is given below.

Funding This work was supported using funds from the Oesterreichische Nationalbank (Anniversary Fund, project number 15346) and the National Institute of Health (NIH) MH113477.

Publisher's Note Springer Nature remains neutral with regard to jurisdictional claims in published maps and institutional affiliations.

The online version of the original article can be found at https://oi.org/ 10.1007/s12281-019-00342-w

Jeffrey D. Jenks

jjenks@ucsd.edu

$\triangle$ Birgit Spiess

birgit.spiess@medma.uni-heidelberg.de

1 Department of Medicine, University of California San Diego, San Diego, CA 92103, USA

2 Department of Hematology and Oncology, Scientific Laboratory, University Hospital Mannheim, Heidelberg University,

Pettenkoferstraße 22, 68169 Mannheim, Germany

3 Section of Infectious Diseases and Tropical Medicine, Medical University of Graz, Graz, Austria 